\title{
E-Mentoring Women: Lessons Learned From A Pilot Program
}

\author{
Joanne D. Leck, University of Ottawa, Canada \\ Catherine Elliott, University of Ottawa, Canada \\ Brittany Rockwell, University of Ottawa, Canada
}

\begin{abstract}
Mentoring has been identified as a key strategy for career development and organizational advancement and has been argued to be indispensable for women to succeed. E-mentoring has increased in popularity as a means of increasing access to mentors, especially female, and reducing some of the challenges associated with being mentored by men. Although access to mentors and mentoring is considerably improved in an e-mentoring environment, it is unclear if the quality and effectiveness of e-mentoring matches traditional mentoring. This qualitative study examines the overall effectiveness of an e-mentoring program focusing on providing psycho-social and career-development support to female mentees, developing trust in a virtual environment, and the mentee/mentor matching process.
\end{abstract}

Keywords: Mentoring; E-mentoring; Women; Career Development; Trust

\section{BACKGROUND}

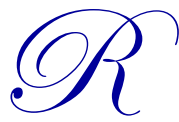

esearch has consistently documented that women are disproportionately represented in upper management and in positions of power and still continue to dominate traditionally 'female' occupations, such as administrative support and service workers (Burke, 2002; Hegewisch, Liepmann, Hayes, and Hartmann, 2010; Hsieh, C-W and Winslow, E., 2006; Jacobs, 1999; Leck, 2002; MacRae, 2005; Shein, Vueller, Lituchy and Liu, 1996). Catalyst, a non-profit organization whose mission is to work with organizations to expand opportunities for women, reported in 2011 that women are underrepresented as heads of the Financial Post Top 500 (FP500) organizations (5.6\% in Canada, 3.2\% in the U.S.), board directors (14\% in Canada, $15.7 \%$ in the U.S.), senior officers (17.7\% in Canada, $14.4 \%$ in the U.S.), and, generally, in management occupations (36.5\% in Canada, $51.5 \%$ in the U.S.), although they represent almost $47 \%$ of the labour force in both countries (Catalyst, 2011a, 2011b). Further, women represent only 6.2\% of the FP500 top earners in Canada and 7.6\% in the U.S. (Catalyst, 2011a, 2011b).

Recognizing that concerted efforts need to be made to assist women in their career development, many organizations have adopted formal mentoring programs which are the most frequently cited organizational practice offered to address gender differences in advancement (Catalyst, 2009a, 2009b; Finkelstein and Poteet, 2007; MacRae, 2005; Orser, 2000).

Mentoring is generally thought of as a relationship between a younger, less experienced individual (i.e., the mentee) and an older, more experienced individual (i.e., the mentor). Mentors provide mentees with psycho-social support, such as friendship and acceptance, as well as career-development support, such as helping the mentee advance in the organization, providing sponsorship and coaching, setting up challenging assignments, fostering positive visibility, and protecting the mentee from adverse forces (Kram, 1983, 1985).

Women who are mentored are more likely than non-mentored women to achieve and obtain career outcomes such as greater compensation, more promotions, higher career satisfaction, increased career and organizational commitment and better work/life balance (Allen, Poteet, Eby, Lentz and Lima, 2004; Eby, Allen, Evans, Ng and DuBois, 2008; Forret and de Janasz, 2005). Mentoring has been argued to be indispensable for 
women (Schein, Mueller, Lituchy, and Liu, 1996) in that it provides them with guidance on how to gain information and insight, seize power, understand organizational politics, obtain feedback and gain access to resources (Burke and McKeen, 1990; Collins, 1983; Headlam-Wells, 2004; Lineham and Walsh, 1999; Ragins, 1996; Ragins and Cotton, 1999).

Research has also demonstrated that mentoring is most effective for women when they are mentored by women. Female mentors can act as role models and have experienced firsthand the difficulties and challenges their mentees currently and will face (Cooper and Hingley, 1983; Tharenou, 2005). Female mentees have less difficulty mirroring 'female behaviors' of female mentors than the 'male behaviors' exhibited by male mentors (Cooper and Hingley, 1983). Women mentored by women report greater interpersonal comfort than do women with male mentors (Allen, Day and Lentz, 2005; Maccoby, 1990) and receive more psycho-social support and careerdevelopment support than do women mentored by men (Fowler, Gudmundsson and O'Gorman, 2007; Okurame, 2007; Ragins and McFarlin, 1990; Scandura, 1992; Scandura and Williams, 2001; Tharenou, 2005; Thomas, 1990).

Unfortunately, the paucity of women in senior roles makes it difficult to guarantee that female mentees will find or have access to female mentors. As a consequence, male mentors may be the only option. However, both male mentors and female mentees may be reluctant to enter into a cross-gender mentoring relationship in case it is misconstrued as a sexual advance or involvement, to avoid office gossip and to appease jealous spouses (Bowen, 1985; Fitt and Newton, 1981; Harden et al., 2009; Hurley, 1996; Morgan and Davidson, 2008; Ragins, 1996; Young, Cady and Foxon, 2006). In fact, Morgan and Davidson (2008) argue that since a good mentoring relationship comes dangerously close to what characterizes a romantic relationship, cross-gender mentorships should be avoided so as to limit the number of opportunities for the mentoring relationship to go wrong. Even when women elect to be mentored by men, finding a male mentor may be problematic because women traditionally have fewer informal and formal opportunities (e.g., having a beer after work, networking on the golf course) to access and interact with potential male mentors (Kram, 1985; Lunding, Clements and Perkins, 1978; O'Brien, Biga, Kesller, and Allen, 2020; Ragins, 1996; Wanberg, Welsch and Heslett, 2003).

\section{E-MENTORING}

The shortage of female mentors and the difficulties associated with cross-gender mentoring has driven the increasing popularity of e-mentoring. Similar to traditional mentoring, e-mentoring is a computer/technology mediated relationship between a senior individual, the mentor, and a less skilled individual, the mentee, with the goal of furthering the mentee in his or her career (Bierema and Merriam, 2002). Participation in an e-mentoring relationship requires computer technology in addition to a basic level of computer literacy (Bierema and Merriam, 2002). Potential mentees search the internet or a mentor database for a mentor or are introduced by a program administrator to potential matches. Administered e-mentoring programs often have forms to complete that are posted online to provide information about participants to assist in creating optimal matches (An and Lipscomb, 2010). Mentors and mentees interact with one another using one or more web tools and means of communication such as email, online discussion groups, instant messaging, chats, video conferencing, skype, blogs, wikis and document sharing (Purcell, 2004).

E-mentoring differs from traditional face-to-face mentoring in three important aspects. First, with ementoring, the pool of potential mentors is global, allowing women to establish mentoring relationships with senior women and female role models that would otherwise be unavailable to them locally (An and Lipscomb, 2010; Bierema and Merriam, 2002). Second, e-mentoring is argued to diminish the effects of social status, age, gender and race (Headlam-Wells, Gosland, and Craig, 2005) as physical characteristics are "less visible in electronic communication, thus rendering them less important to the overall exchange" (Bierema and Merriam, 2002, p. 221). As a consequence, female mentees can be mentored by men without the negative ramifications that challenge crossgender mentoring relationships. Third, e-mentoring allows both mentors and mentees to access more than one mentor or mentee at a time, thereby broadening professional networks and providing participants with multiple perspectives on any given situation (An and Lipscomb, 2010).

Although access to mentors and mentoring is considerably superior in an e-mentoring environment, it is unclear if the quality and effectiveness of e-mentoring matches traditional mentoring. An and Liscomb (2010) argue 
that the quality of communication increases with e-mentoring in that participants become more intentional in their communications and spend more time collaborating and reflecting rather than merely exchanging information with one another. E-mentoring also provides a record of correspondence allowing both the mentor and mentee to keep track of their interactions and refer to them when needed (Headlam-Wells et al., 2005). Additionally, the technology component of an e-mentoring relationship allows for more candid communication (Bierema and Merriam, 2002) and can assist individuals who might be reluctant to express certain thoughts or ideas in a face-to-face interaction (An and Lipscomb, 2010). Conversely, Purcell (2004) argues that e-mentoring relationships may be harder to develop than traditional face-to-face mentoring relationships, given that the majority of the communication lacks nonverbal cues, such as pitch of voice, flow of speech, facial expression, and body language, thereby making it easy for participants to misinterpret meanings and feelings conveyed in communications. Further, participants may also be overwhelmed with the amount of information that can be exchanged or with the frequency and different means of communications employed (Bierema and Merriam, 2002).

Given that there appear to be both advantages and disadvantages to communicating electronically, it is unclear if e-mentoring communicates the required career-development and psycho-social support that is key to attaining mentoring objectives. Because career-development support is so essential for women to advance in their careers (Tharenou, 2005), it is especially important to ascertain if this form of support is communicated effectively in an e-mentoring environment.

Difficulties in communication can also impact the development of the mentee/mentor relationship. For instance, trust has been demonstrated to be an essential element of a mentoring relationship (Elliott, Leck, Orser and Mossop, 2007; Leck and Orser, 2012). According to Mayer, Davis and Schoorman (1995), trust is a function of the trustor's perception of the trustee's ability, benevolence, and integrity. These perceptions are more easily formed in traditional face-to-face mentoring as the communication is richer in content and there are more opportunities to demonstrate ability, integrity, and benevolence. Further, because traditional mentoring programs usually involve mentees and mentors from the same organization, more is known about the mentor's ability, integrity, and benevolence prior to matching, so mentees enter the relationship with a certain level of trust in their mentor. Contrarily, in e-mentoring, mentees and mentors know very little about each other and are limited to text, such as profiles, curriculum vita, and websites. It is therefore unclear how mentee/mentor trust is formed in a virtual environment. What triggers the formation of perceptions of ability, integrity, and benevolence? That is, in the absence of face-to-face contact, what do mentees rely on to form these perceptions that in turn establish trust?

Therefore, the purpose of this research is to shed light on these issues by evaluating the overall effectiveness of a pilot e-mentoring program focusing on providing psycho-social and career-development support to female mentees and developing trust in a virtual environment. The overall effectiveness of the e-mentoring program and the effectiveness of the matching process will also be examined. An exploratory qualitative approach was chosen due to lack of research in this area.

\section{METHODOLOGY}

\section{Sample}

The sample consisted of individuals working in the technology sector who had participated in a one-year cross-organizational pilot e-mentorship program administered by Canadian Women in Technology (CanWIT) - an organization dedicated to support the career development of women in technology. The mentors were both male and female and were recruited through the Chief Information Officer Association of Canada (CIOCAN) - a not-for-profit community of Information Technology (IT) leaders whose mission includes facilitating networking, sharing of best practices, and executive development. Mentees, all of whom were female, were selected by an application review process conducted by CanWIT's project directors. Mentees and mentors were matched by CanWIT based on the program director's assessment of which CIOCAN member could offer the best guidance to each mentee. After a 'kick-off' meeting where mentors and mentees met face-to-face, all subsequent communication was conducted electronically. In all, nine mentoring dyads were formed for the pilot program. Some participants declined to participate in the study, leaving a sample of six mentees and seven mentors (three female and four male). Of the mentors who declined to participate, one was male and the other female. 


\section{Procedure}

Mentors and mentees were informed by the project director that they would be contacted by telephone and asked questions about the e-mentoring experience as part of the pilot's evaluation process. Mentors and mentees were subsequently contacted by email and requested to participate in the evaluation. If they agreed to participate, a mutually agreed-upon time for the telephone interview was established. Semi-structured interviews lasted about 45 minutes each. Participants were told that their responses would be kept confidential and that any printed quotes would be anonymous. Telephone interviews were recorded and transcribed verbatim. Because of the small sample size, qualitative software was not required. Similar responses were grouped together and categorized.

\section{Interview Protocol}

Subjects were asked questions (see Appendix) about the goal of the program (question 1), the challenges faced before entering the program (questions 2-4), the career-development support provided/received (questions 57), the psycho-social support provided/received (question 8), the impact of the mentee/mentor match (questions 913), the level of trust in the mentoring relationship (questions 14-15), and the overall evaluation of the e-mentoring pilot program (questions 16-19).

\section{RESULTS AND DISCUSSION}

\section{Career-development Support}

Mentees were generally satisfied with what their mentors did to support them in managing and developing their careers (career-development support). While two mentees gave only general evaluations of the level of careerdevelopment support (e.g., "very supportive and very encouraging"), the remaining mentees provided detailed examples (e.g., "put in plugs in own his own company", "worked together to determine what program goals were and developed a plan", and "was able to provide perspective on how to approach things strategically"). The career benefits of e-mentoring reported by all six mentees were improved - career planning, networking, confidence, communication skills, relationships with top management, and strategic thinking. In addition, all the mentees saw themselves in leadership roles within five years.

The forms of career-development support mentors believed they offered included asking 'hard' probing questions to increase self-awareness (e.g., "How do you display you're a leader?"), recommending conferences and critical reading material, providing feedback, helping solve problems, developing strategic thinking, and providing network management strategies. They felt that their mentoring resulted in positive differences and that their mentees displayed more confidence and control over their lives as well as enjoyed increased visibility and promotability (in fact, two of the mentees were promoted to new roles during the pilot). Further, mentors believed that within five years, their mentees would be occupying new roles (i.e., moving away from the technical side) and more senior managerial roles.

Therefore, these results suggest that both male and female mentors are able to provide career-development support to their mentees in an e-mentoring environment.

\section{Psycho-social Support}

In terms of psycho-social and emotional support, mentee responses differed by mentor gender - mentees with female mentors indicated that their mentors were "very supportive and understanding" and one mentee complained that her mentor was "too supportive" and "didn't give out constructive criticism and feedback." Mentees with male mentors did not provide evidence of having received any psycho-social or emotional support, and in one instance, the mentee articulated that her mentor "never developed me emotionally".

Mentors - both male and female - were less vocal about the amount and type of psycho-social support they

offered. Instead, most of their discussions centered around career-development support. Mentors indicated briefly 
that they listened to their mentees concerns and frustrations, helped them deal with stressors (e.g., work/life balance), offered support and encouragement (e.g., "You can do it!"), and helped build their confidence.

The results suggest that mentors and mentees differed with respect to their perceptions of the amount of psycho-social support provided. While mentors spoke sparingly about providing psycho-social support, mentees complained that they had too much (with female mentors) or too little (with male mentors). Although previous research suggests that women are more in need of career-development support than psycho-social support to climb the corporate ladder (Tharenou, 2005), psycho-social support remains an important mentoring function. Although ementoring appears to be effective in delivering career-development support, mentors should be reminded that psycho-social support is also a necessary mentoring function.

\section{Trust}

Only one mentee indicated that trust was problematic in the relationship. She cited two reasons to explain the diminished level of trust - perceived lack of commitment ("didn't feel like she put in the effort") and worries that her mentor would not keep discussions in confidence ("I was divulging information to her about my industry. I wasn't sure she would keep it to herself"). A summary of what triggered trust among mentees is listed in Table 1 categorized by Procedural Triggers and Mayer et al.'s (1995) three predictors of trust; namely, Ability, Integrity, and Benevolence. For instance, trust was formed through procedures such as outlining clear expectations from the start ("it's like a contract"). Mentors established their ability by demonstrating expertise ("most discussions revolved around work-related topics"), their integrity by keeping confidences ("didn't spill the beans on personal information with other mentors"), and their benevolence by being approachable and welcoming ("happy to talk to me", "never felt like it was rushed", and "very relaxed"). More examples were provided describing the mentor's benevolence than the mentor's ability or integrity. Some mentees also indicated that they trusted their mentor due to a 'feeling' (e.g., "feeling that there is a connection", "when you feel comfortable with a person, you know it's a good matching", and "good potential for friendship").

Table 1: Triggers Establishing Trust

Procedural

- $\quad$ signing a confidentiality/ethics statement

- $\quad$ outlining clear expectations from the start ("It's like a contract")

- $\quad$ structuring the mentoring process (e.g., "Schedules were stable (once a week)")

- $\quad$ conducting face-to-face meetings ("Met for coffee for an hour once a month. If she had only communicated by phone or emails, it might have been a different relationship", "Meeting in person is special")

- $\quad$ attending mentoring program events (e.g., the kick-off meeting)

Establishing Ability

- $\quad$ successfully achieving the mentee's goals ("Came up through the company in the same way. Same humble beginnings")

- demonstrating expertise ("Most discussions revolved around work-related topics")

- $\quad$ gave information and reading material

Establishing Integrity

- $\quad$ keeping confidences ("... didn't spill the beans on personal information with other mentors")

- demonstrating commitment ("Follow promises", Never rescheduled")

• $\quad$ being reachable/available ("Frequent communications", "Regular meetings")

Establishing Benevolence

- $\quad$ encouraging connections

- $\quad$ being approachable and welcoming ("Happy to talk to me", "Never felt like it was rushed", "Very relaxed")

- $\quad$ establishing a 'personal' connection ("We always began discussions asking about each other's kids. It made me feel more comfortable when approaching the more difficult topics...")

- demonstrating a genuine interest in the mentee's success (" It felt like the mentee was put first", "Mentor vocalised that it was win-win for learning of company and mentees.")

- $\quad$ sharing personal stories 
When mentors were asked what created an atmosphere of trust between themselves and their mentees, they all discussed their perceptions of being considered 'trustworthy' by their mentees; no mentors discussed their own trust in their mentees. Mentors felt that their mentees trusted them when they (mentors) were prepared to listen, were non-judgemental, shared personal experiences, and interacted frequently with their mentees (all indicators of benevolence). Further, mentors indicated that their mentees trusted them when their mentees shared personal stories, disclosed their vulnerabilities and weaknesses, and asked questions (behaviours anticipating a benevolent mentor). Although mentors did not comment on the trust they felt for their mentees, they all indicated that they enjoyed good working relationships and that some considered their mentees to be friends. Reasons cited for the development of trusting relationships included being transparent, frequency of interactions, the mentee acting on the advice given and similar backgrounds.

These results suggest that although establishing mentor ability and integrity are important for creating an atmosphere of trust, establishing mentor benevolence is key. As a result, ways to demonstrate mentor benevolence should be implemented early on in the mentoring program. Mentors should be instructed to share personal stories and provided with strategies and tactics to convey being approachable and welcoming. The lack of responses regarding mentor trust in their mentee suggests that reciprocal trust may not be required in an e-mentoring environment. Alternatively, it may be because mentors and mentees worked in different organizations, mentoring failures (e.g., dysfunctional relationships, making the mentor look bad, divulging confidences) would have little impact on the mentor's reputation, so trusting the mentee may not be a requirement.

\section{Matching}

Mentees identified differences between themselves and their mentors (e.g., different ambitions, years of experience, decision-making styles, community involvement, emotional intelligence, technical expertise, leadership level and styles, assertiveness). Mentees indicated that these differences helped in giving them a new and different perspective (e.g., "... having those differences is what I needed in order to move forward"). However, one mentee who felt that she was not receiving enough meaningful feedback, stated that the differences between herself and her mentor created 'boundaries'. In every case, these impressions were formed at the very beginning in the initial 'kickoff' meeting and were based on the mentor's presentations and initial conversations.

When asked how they were similar to their mentors, mentees cited drive (especially regarding their careers), ambition, directness, personality characteristics (e.g., extroversion, friendliness), openness, communication skills, as well as some demographic characteristics such as gender, parental status, geographic origin, and work sector. In every case, the mentee's perceived similarity to their mentor resulted in increased comfort with the relationship ("helped to be more open with each other and exchange thoughts", "similar personality types and backgrounds build a common ground", and "open up doors to communication more"). Again, as was the case for perceived differences, perceptions of similarity were formed at the beginning of the relationship during the first contact.

To further investigate how mentees and mentors should be matched, mentees were asked to describe themselves as a mentee, to describe the perfect mentor, and to describe how they would like their next mentor to be different. Mentees described themselves as being open, eager to learn, and goal-oriented. The perfect mentor was described as someone who performed both career-development and psycho-social functions (see Table 2). Although there was general consensus that a mentor should also possess the personal characteristics listed in Table 2, only one mentee cited gender and differing personality as a desired attribute. When asked how they would like their next mentor to be different, one mentee (who had been mentored by a woman) indicated that she desired a male mentor in order to obtain a different perspective. 
Table 2: Describe the Perfect Mentor (Mentee Perspective)

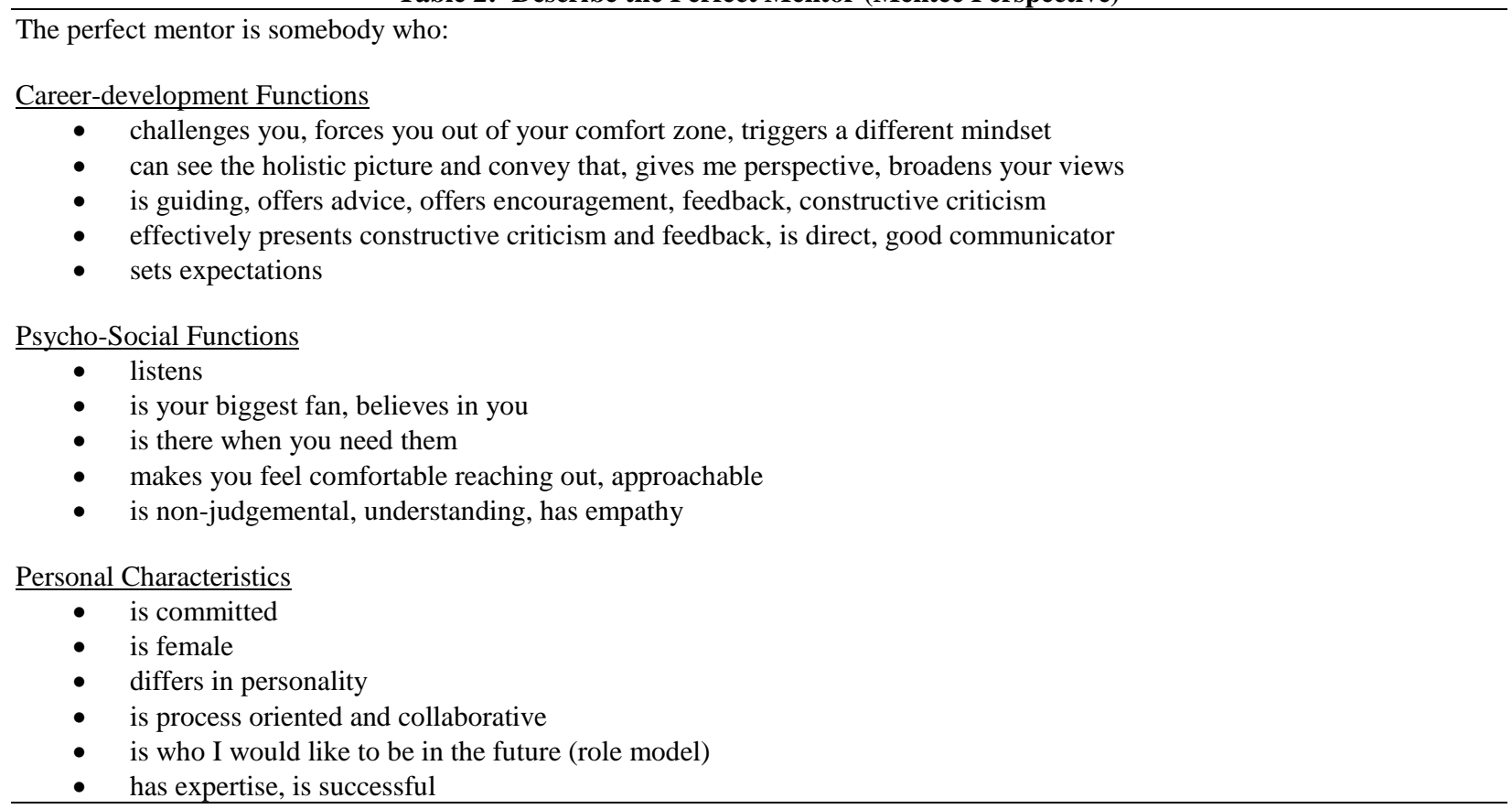

What were the mentors' perspectives? When asked to discuss on what dimensions they felt they were different when compared to their mentees, they described their mentees as younger, less experienced, less savvy, less confident, and more conservative. One mentor offered gender as a difference. Mentors noted that it was important to understand and work through these differences ("it was a question of understanding these differences", "needed to be aware of my boundaries") and that these differences either helped the mentoring experience ("you can't learn anything from the same person") or hindered it ("mentee felt uncomfortable trying the things I suggested"). These differences became apparent very early on in the relationship and usually during the initial introduction.

Mentors indicated that they also perceived similarities between themselves and their mentees, both on a personality level (e.g., ambitious, energetic, passionate, entrepreneurial) as well as similarity in background (e.g., family status, geographic origin, business sector, outside activities). In all cases, these similarities helped the relationship ("could understand what the mentee was talking about", "more balanced", "easier to establish trust", and déjà-vu moments"). Unlike perceptions of mentor/mentee differences that were established early on, perceived similarities became apparent further into the mentoring process and, in one case, not until the end of the program when "results started being noticed". Although most mentors could not recall a specific event when these similarities became apparent, two mentors (both women) cited events where discussions became more personal in nature.

Again, to further investigate how mentees and mentors should be matched, mentors were asked to describe themselves as a mentor, to describe the perfect mentee, and to describe how they would like their next mentee to be different. Mentors concentrated on describing the 'perfect mentor' as someone possessing certain personal and personality characteristics and less on their ability to perform career-development or psycho-social functions (see Table 3). The perfect mentee was described as someone who is willing to learn, recognizes their own shortcomings, listens and follows through, and knows that to make changes is hard work. Mentors were dissatisfied with their mentees' commitment and willingness to change. 
Table 3: Describe the Perfect Mentor (Mentor Perspective)

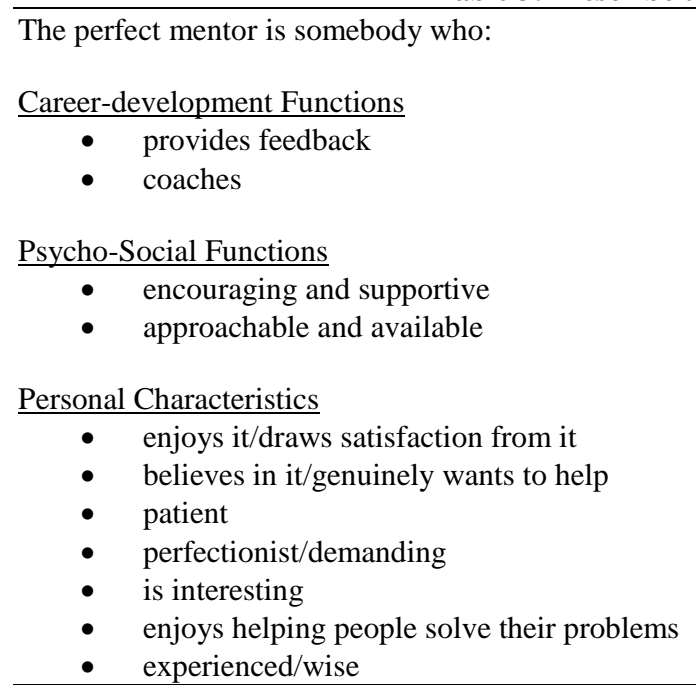

The results suggest that it is inconclusive if mentor/mentee differences help or hinder the relationship. Perhaps it does not matter; every match results in a new perspective and a mentorship that is not working simply means that the program director should intervene and create a new pairing. An interesting result was that these perceptions were formed early on. Since first impressions can be misleading, program directors should provide as much information about the mentor/mentee early on (e.g., curriculum vitae, personal web pages, etc.) to attempt to increase the validity of first impressions.

While perceived differences either helped or hindered the mentoring experience, perceived similarities only helped. Again, program directors should ensure that both mentors and mentees are aware of any similarities early on in the relationship. The results also suggest that personal discussions promote the identification of apparent similarities. Mentors and mentees should be aware of this during training.

While both mentees and mentors described the 'perfect mentor' as someone who provides both careerdevelopment and psycho-social support, mentors also stressed that the 'perfect mentor' is someone who has a genuine interest in helping. With the ever-increasing need for mentors, program directors should emphasize the many positive benefits to mentoring (e.g., immortalizing their expertise, moulding future leaders, etc.) to potential mentors to increase their propensity to enter this role. Finally, both mentors and mentees described the 'perfect mentee' as someone who is open and willing to learn. Unfortunately, mentors were dissatisfied with their mentees' openness and willingness to learn. The importance of being open and willing to change should be emphasized and promoted before mentoring starts (e.g., during training, using contracts, etc.).

\section{Overall Evaluation Of The E-Mentoring Program}

Mentees cited coordination and scheduling difficulties as both weaknesses and strengths of e-mentoring, although they were cited as strengths far more frequently (e.g., "face to face meetings would have been very challenging", "no location restrictions", and "huge advantage for people coming from remote locations"). Interestingly, one mentee remarked that with e-mentoring, it would be much easier to exit the relationship, if it became dysfunctional ("If you don't want the relationship to work, it is much easier to block out."). Mentees also expressed the lack of face-to-face meetings as a disadvantage; especially if the mentee and/or mentor were not good communicators ("body language cannot be seen over e-mentoring"). Finally, Table 4 outlines the recommendations mentees made to improve future e-mentoring endeavours. 
Table 4: E-mentoring Program Requirements

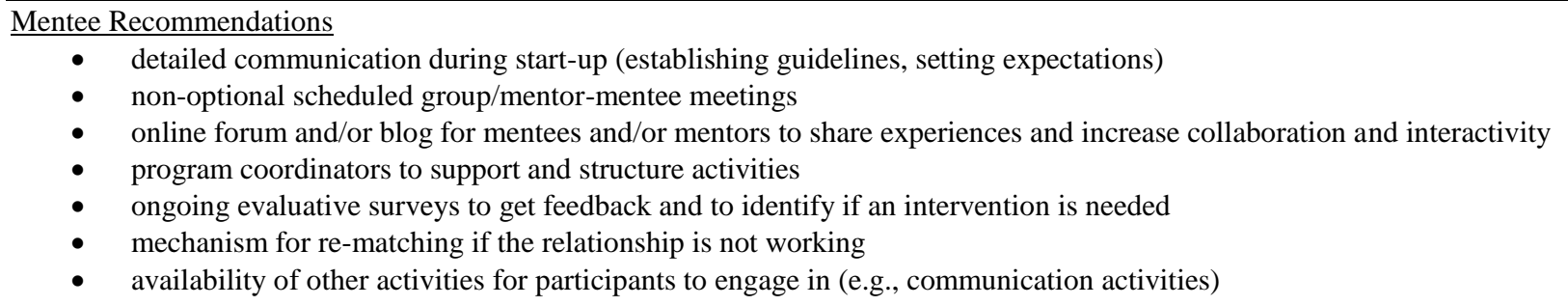

Mentor Recommendations

- $\quad$ more structure and resources (staff) to administer the program

- $\quad$ pre-established points where feedback is gathered/regular 'check-ins'

- $\quad$ skype/video conferences for more emotional connections and body language

- $\quad$ events where mentors and mentees can meet

- $\quad$ guided conversations during the initial meeting

- forum for mentors to exchange information with one another

- forum for mentees to exchange information with one another

- $\quad$ ongoing and regular program evaluations

Although all of the mentors had mentored previously, this was their first experience in a formal mentoring program, as well as their first experience with mentoring in a virtual environment. All mentors indicated that using mentoring via email had positive consequences ("easier to arrange phone calls and email", "didn't have to move around as much", "time commitment was less", "work/life balance", "it was a safe environment"), although it took some time to get adjusted to ("... it falls in suite with any mentoring once you get in the swing"). The major disadvantage mentors cited was the lack of face-to-face encounters ("I wish I could see the body language", "deeper connections when you see them face-to-face", and "conversation in person would have added another level of connection"). Other difficulties mentors faced in the pilot program included establishing trust, losing contact with the mentee ("...wasn't sure if I should reach out to her (mentee) or not", "... losing track towards the end. She [mentee] dropped away") and not knowing how to deal with a mentee's personal issues. Suggestions made by mentors to improve the quality of the e-mentoring experience are also reported in Table 4.

Both mentors and mentees felt that e-mentoring's primary advantage was the ease with which mentoring could occur and that this advantage came at the cost of less face-to-face contact. Mentors and mentees also provided similar responses when making recommendations on how to improve the e-mentoring experience and cited the need for more structure (e.g., scheduled meetings and activities), more resources (i.e., program coordinators), online forums, and ongoing evaluations. Mentees also offered the need to set expectations at the start-up and to provide a mechanism to exit the relationship should it become dysfunctional. Both of these recommendations reduce the risk in the mentoring relationship suggesting that mentees may be somewhat apprehensive of entering an e-mentoring relationship.

\section{CONCLUSION}

Despite the small sample size, several lessons can be learned from the results of this study which could be incorporated into the launch of the next phase of the program and the development of other e-mentoring programs.

First, although e-mentoring may not present any barriers or obstacles in providing career-development support, there may be more challenges with respect to providing psycho-social support. During initial training and orientation sessions, mentors should be made of aware of the types of support they should be providing and why both forms are important. Program coordinators should assess the extent to which both career-development and psycho-social support are provided during the program's periodic review and then intervene when required.

Second, establishing mentor benevolence appears to be a key ingredient in creating a trusting environment. Unfortunately, establishing benevolence in a virtual environment can be challenging. This emphasizes the importance of an initial face-to-face meeting and the use of technologies that emulate face-to-face (e.g., skype). 
Mentors should also receive training on how to trigger perceptions of their benevolence to their mentees (e.g., the importance of sharing personal stories). It is not clear why a mentor's trust in their mentee was not articulated during the interviews. Future research should examine how a mentor's trust in their mentee is formed in an e-mentoring environment and what impact reciprocal trust has on the effectiveness of the mentoring relationship.

Third, this study sheds light on how to best match mentors and mentees in an e-mentoring environment. Matching on similarities appears to increase the rapport between mentor and mentee, and given that rapport may be more difficult to accomplish in a virtual environment, establishing similarities early on is beneficial. Because some differences between mentors and mentees can also be beneficial (e.g., different work styles, perspectives), program coordinators could include demographic similarities in their matching process (e.g., sports interests, home towns, etc.) which would not impact the learning experience as much. Further, since perceptions of similarities and differences were formed very early in the mentoring relationship, program coordinators should ensure that the similarities are known in the start-up meeting (preferably 'in person' meetings). Mentors expected their match to be open and accept advice; however, even though mentees admitted that these were desirable characteristics, mentors were dissatisfied with their mentee's behaviour. It may be easier for mentees to not follow through with their mentor's instructions in a virtual environment, as potentially embarrassing face-to-face meetings where mentees would have to admit not following through are avoided. In other words, e-mentoring may prove less forceful and demanding than traditional mentoring relationships. To mitigate this problem, mentee expectations and objectives should be clearly laid out during initial training and orientation and mentees should sign a contract or a pledge committing themselves to be open to their mentor.

Finally, while generally satisfied with the benefits of e-mentoring, participants of the pilot program felt strongly about the need for additional structure and resources. This suggests that e-mentoring programs have to be even more 'formal' than traditional formal mentoring programs and, consequently, e-mentoring may be more costly and challenging to operate. Also, while e-mentoring may reduce the difficulty of exiting a dysfunctional relationship (e.g., lower likelihood of mentor backlash, no uncomfortable 'run-ins' with the mentor), formalizing expectations and exit procedures may further increase the attractiveness to mentees and thereby increase the likelihood that aspiring young women will seek mentoring.

Although research examining the effectiveness of e-mentoring in advancing the careers of young women is in its infancy, it appears to have a promising start. More research is needed to examine differences in e-mentoring objective career outcomes (e.g., pay, promotions, retention, etc.) between same-gender and cross-gender dyads to identify what resources and training mentees and mentors need to maximize the effectiveness of virtual mentoring and to compare the effectiveness of e-mentoring to traditional mentoring.

\section{AUTHOR INFORMATION}

Dr. Joanne Leck, Ph.D. (McGill University) joined the Telfer School of Management in 2000 as a professor of human resource management and organizational behaviour. Dr. Leck obtained a B.Math from the University of Waterloo in 1980, an MBA from McGill University in 1987 and a Ph.D. from the same university in 1992. Her thesis examined the effectiveness of employment equity programs and issues related to managing diversity. Dr. Leck's earliest work was an extension of her dissertation, where she continued to research employment and pay equity. After interviewing women who broke the glass-ceiling, she became increasingly aware of another problem women face in the workplace, namely bullying and harassment. As these working conditions may dissuade women from advancing in their careers, she turned her attention to this area of research. Most recently, she has been investigating how mentoring can not only protect women from any adverse forces but also provide them with the psycho-social and career support they need to advance. Dr. Leck is currently the Principal Investigator of two SSHRC grants supporting this mentoring research. In addition to her academic experience, Dr. Leck worked for several years at Air Canada in Information Technology and has provided training in negotiation skills and managing diversity for a variety of organizations, including Canada Post, Hydro Quebec, le Cirque du Soleil and the University of Havana. E-mail: leck@telfer.uottawa.ca (Corresponding author)

Professor Catherine Elliott, Ph.D. (University of Ottawa) has focused her research on improving organizational performance in three main areas: human resources, performance management, and women's entrepreneurship. In the 
area of human resources, she has conducted research on mentoring and trust, adult learning, e-mentoring, and career development. In performance management (PM), she has been involved in the Interis Research cluster, investigating PM in the federal public sector. In women's entrepreneurship, she has co-authored several academic articles about gender and entrepreneurial identity. Professor Elliott teaches Organizational Behaviour, Human Resources Management and Organization Design in the undergraduate and MBA programs. Over the last 20 years, she has also worked as a human resource manager and management consultant. As an HR manager, she worked in a variety of corporate roles, across many functions, from executive recruiting to staffing. As a consultant, she provided services to federal government clients in training and education, career development, and change management. E-mail: elliott.young@sympatico.ca

Brittany Rockwell, (University of Ottawa) has been a research associate under the supervision of Dr. Leck since 2010. She has conducted research on both traditional mentoring and e-mentoring in this time. Her contributions are related to the promotion of women in leadership roles, gender differences in e-mentoring and traditional mentoring, and the development and integration of organizational e-mentoring schemes. She has worked alongside Canadian Women in Technology to aid in the development and evaluation of e-mentoring programs designed for women looking to advance in information technology. As she currently continues her academic research, she is working towards completing her Bachelor of Commerce in Finance at the Telfer School of Management and later plans to matriculate to law school. E-mail: Rockwell@ @elfer.uottawa.ca

\section{ACKNOWLEDGEMENTS}

The authors would like to thank the Social Sciences and Humanities Research Council of Canada for funding of this project.

\section{REFERENCES}

1. Allen, T.D., Day, R., and Lentz, E., 2005. The role of interpersonal comfort in mentoring relationships. Journal of Career Development, 31(3), 155-169.

2. Allen, T.D., Poteet, M.L., Eby, L.T., Lentz, L.L., and Lima, L., 2004. Career benefits associated with mentoring for mentees: A meta-analysis. Journal of Applied Psychology, 89(1), 127-136.

3. An, S and Lipscomb, R., 2010. Instant Mentoring: Sharing Wisdom and Getting Advice Online with eMentoring. Journal of the American Dietetic Association, 110(8), 1148-1155.

4. Bierema, L. and Merriam, S., 2002. EMentoring: Using Computer Mediated Communication to Enhance the Mentoring Process. Innovative Higher Education, 26(3), 211-227.

5. Bowen, D.D., 1985. Were men meant to mentor women? Training and Development Journal, 39(2), 31-40.

6. Burke, R.J., 2002. Career development of managerial women. In R.J. Burke and D.L. Nelson, (Eds.), Advancing women's careers: Research and practice. Oxford, UK: Blackwell, 32-46.

7. Burke, R.J., and McKeen, C.A., 1990. Mentoring in organizations: Implications for women. Journal of Business Ethics, 9, 317-322.

8. Catalyst, 2011a. http://www.catalyst.org/publication/132/us-women-in-business

9. Catalyst, 2011b.. http://www.catalyst.org/publication/198/canadian-women-in-business

10. Collins, N.W., 1983. Professional women and their mentors. Englewood Cliffs, NJ: Prentice-Hall.

11. Cooper, C.L. and Hingley, P., 1983. The Change Makers. London, UK: Harper and Row.

12. Deaux, K., and Emswiller, T., 1974. Explanation of successful performance on sex-linked tasks: What is skill for the male is luck for the female. Journal of Personality and Social Psychology, 29, 80-85.

13. Eby, L. T., Allen, T. D., Evans, S. C., Ng, T., and DuBois, D. L., 2008. Does mentoring matter? A multidisciplinary meta-analysis comparing mentored and non-mentored individuals. Journal of Vocational Behavior, 72(2), 254.

14. Elliott, C., Leck, J.D., Orser, B., and Mossop, C., 2007. An exploration of gender and trust in mentoring relationships. Journal of Diversity Management, 1(1), 1-11.

15. Feng, J., and Lazar, J. and Preece, J., 2004. Empathy and online interpersonal trust: A fragile relationship. Behaviour and Information Technology, 23(2), 97-106. 
16. Finkelstein, L., and Poteet, M., 2007. Best practices for workplace formal mentoring programs. In T.A. Allen and L.T. Eby (Eds.), The Blackwell handbook of mentoring: A multiple perspectives approach. London, UK: Blackwell, 345-368.

17. Fitt, L.W., and Newton, D.A., 1981. When the mentor is a man and the mentee is a woman. Harvard Business Review, 59, 56-60.

18. Forret, M., and de Janasz, S., 2005. Perceptions of an organization's culture for work and family: Do mentors make a difference? Career Development International, 10(6/7), 478-492.

19. Fowler, J.L., Gudmundsson, A.J., and O'Gorman, J.G., 2007. The relationship between mentee - mentor gender combination and the provision of distinct mentoring functions. Women in Management Review, 22(8), 666-681.

20. Hegewisch, A., Liepmann, H., Hayes, J., and Hartmann, H., 2010. Separate and not equal? Gender segregation in the labor market and the gender wage gap. Institute for Women's Policy Research, Briefing Paper IWPR C377, www.iwpr.org

21. Harden, S.L., Clark, R.A., Johnson, B., and Larson, J., 2009. Cross-gender mentorship in clinical psychology doctoral programs: An exploratory survey study. Mentoring and Tutoring: Partnership in Learning, 17(3), 277-290.

22. Headlam-Wells, J., 2004. EMentoring for aspiring women managers. Women in Management Review, 19(4), 212-218.

23. Headlam-Wells, J., and Gosland, J. and Craig, J., 2005. "There's magic in the web": EMentoring for women's career development. Career Development International, 10(6/7), 444-459.

24. Horgan, D.D., and Simeon, R.J., 1990. Gender, mentoring and tacit knowledge. Journal of Social Behavior and Personality, 5(4), 453-471.

25. Horgan, D.D., and Simeon, R.J., 1991. The downside of mentoring. Performance + Instruction, 30(1), 3435 .

26. Hsieh, C-W., and Winslow, E., 2006. Gender representation in the federal workforce. Review of Public Personnel Administration, 26(3), 276-295.

27. Hurley, A.E., 1996. Challenges in cross-gender mentoring relationship: Psychological, intimacy, myths, rumors, innuendoes and sexual harassment. Leadership and Organization, 17(3), 42-50.

28. Jacobs, S., 1999. Trends in women's career patterns and in sex occupational mobility in Britain.

29. Kram, K.E., 1983. Phases of the mentor relationship. Academy of Management Journal, 26, 608-625.

30. Kram, K.E., 1985. Mentoring at work: Developmental relationships in organizational life. Glenview, IL: Scott Foresman.

31. Leck, J.D., 2002. Making Employment Equity Programs work for women. Canadian Public Policy, 28, 85100 .

32. Leck, J.D., and Orser, B., in press. Fostering Trust in Mentoring Relationships: An Exploratory Study, Equality, Diversity and Inclusion: An International Journal.

33. Lineham, M. and Walsh, J.S., 1999. Mentoring relationships and the female managerial career. Career Development International, 4(7), 348-352.

34. Lunding, F.J., Clements, G.L., and Perkins, D.S., 1978. Everyone who makes it has a mentor. Harvard Business Review, 56(4), 89-101.

35. Macoby, E.E., 1990. Gender and relationships: A developmental account. American Psychologist, 45, 513520 .

36. MacRae, N., 2005. Women and work: A ten year retrospective. Work, 24, 331-339.

37. Mayer, R.C., Davis, J.H., and Schoorman, F.D., 1995. An integrative model of trust formation. Academy of Management Review, 20(3), 709-734.

38. Morgan, L. M., and Davidson, M. J., 2008. Sexual dynamics in mentoring relationships - A critical review. British Journal of Management, 19(Supplement 1), S120-S129.

39. Noe, R.A., 1988. Women and mentoring: A review and research agenda. Academy of Management Review, $13,65-68$.

40. O'Brien, K.E., Biga, A., Kesller, S.R., and Allen, T.D., 2010. A meta-analytic investigation of gender differences in mentoring. Journal of Management 36(2), 537-554.

41. Okurame, D.E., 2007. Perceived mentoring functions: does mentor's gender matter? Women in Management Review, 22(5), 418-427. 
42. Orser, B., 2000. Creating high-performance organizations: Leveraging women's leadership. Ottawa: The Conference Board of Canada.

43. Purcell, K., 2004. Making eMentoring more effective. Am J Health-Syst Pharm, 61, 284-286.

44. Ragins, B.R., 1996. Jumping the hurdles: Barriers to mentoring women in organizations. Leadership and Organization Development, 17(3), 37-44.

45. Ragins, B.R., 2002. Diversified mentoring relationships in organizations: A power perspective. Academy of Management Review, 22,482-521.

46. Ragins, B.R., and Cotton, J.L., 1999. Mentor functions and outcomes: A comparison of men and women in formal and informal mentoring relationships. Journal of Applied Psychology, 84(4), 529-550.

47. Ragins, B.R., and McFarlin, D.B., 1990. Perceptions of mentor roles in cross-gender mentoring relationships. Journal of Vocational Behaviour, 37, 321-339.

48. Scandura, T.A., 1992. Mentorship and career mobility: An empirical investigation. Journal of Organizational Behavior, 13, 169-174.

49. Scandura, T.A., and Williams, E.A., 2001. An investigation of the moderating effects of gender on the relationships between mentoring initiation and mentee perceptions of mentoring functions. Journal of Vocational Behavior, 59, 342-363.

50. Schein, V.E., Mueller, R., Lituchy, T., and Liu, J., 1996. Think manager - think male: A global phenomenon? Journal of Organizational Behavior, 17, 33-41.

51. Tharenou, P., 2005. Does mentor support increase women's career advancement more than men's? The differential effects of career and psychosocial support. Australian Journal of Management, 30(1), 77-109.

52. Thomas, D., 1990. The impact of race on managers' experiences of development relationship (mentoring and sponsorship): An intra-organizational study. Journal of Organizational Behavior, 11, 479-492.

53. Urban, G., and Amyx, C. and Lorenzon, A., 2009. Online Trust: State of the Art, New Frontiers, and Research Potential. Journal of Interactive Marketing, 23, 179-190.

54. Wanberg, C.R., Welsh, E.T., and Hezlett, S.A., 2003. Mentoring research: A review and dynamic process model. Research in Personnel and Human Resource Management, 22, 39-124.

55. Young, A., Cady, S., and Foxon, M., 2006. Demystifying gender differences in mentoring: Theoretical perspectives and challenges for future research on gender and mentoring. Human Resource Development Review, 5, 148-175.

56. Young, M. and Tseng, F., 2008. Interplay between Physical and Virtual Settings for Online Interpersonal Trust Formation in Knowledge-Sharing Practice. 11(1), 55-64. 


\section{APPENDIX}

\section{Pilot Evaluation - Mentees/Mentor Interview Questions}

1. For you, what was the goal of the program?

2. What sort of mentoring did you receive before this program? What sort of mentoring did you provide before this program? How did it compare to e-mentoring?

3. What were the issues and challenges of finding an appropriate mentor before the program? What issues and challenges do you think your mentee faced before entering the program?

4. Was gender an issue in finding an appropriate mentor and why? Was your mentee's gender an issue in being able to find an appropriate mentor and why?

5. What did your mentor do to support you in managing and developing your career? What sort of support did you offer your mentee to help her manage and develop her career?

6. How did the mentoring experience make a positive difference to you and your career? How did the mentoring experience make a positive difference to your mentee and her career?

7. What do you see yourself/your mentee doing five years from now? How would this five-year plan be different had you/she not participated in the mentorship program?

8. What did your mentor do to provide you with emotional and psychological support? What emotional and psychological support did you provide your mentee?

9. On what dimensions would you say you were very different from your mentor/mentee? (Probe for 3). For each dimension: a) how did this help or hinder the relationship? b) when did the influence of this difference become apparent? c) can you recall a specific event that brought this to your attention?

10. On what dimension would you say you were very similar to your mentor/mentee? (Probe for 3). For each dimension: a) how did this help or hinder the relationship? b) when did the influence of this difference become apparent? c) can you recall a specific event that brought this to your attention?

11. Describe yourself as a mentee/mentor.

12. Describe the perfect mentor/mentee.

13. On what dimensions would you like your next mentor/mentee to be different?

14. What created an atmosphere of trust between you and your mentor/mentee? Can you give specific examples?

15. Did you feel you had a deep level of connection with your mentor/mentee? How would you describe the connection? Give an example of what exemplifies the connection. What occurred to establish this connection? OR What prevented a deep level of connection from occurring?

16. What difficulties did you face in your mentoring relationship? How did you resolve them?

17. What were the advantages of e-mentoring vs. face-to-face mentoring?

18. What were the disadvantages of e-mentoring vs. face-to-face mentoring?

19. What could have been done to improve the quality of the e-mentoring experience? 